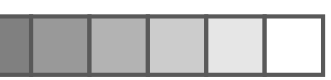

\title{
La Protección de los derechos socio- ambientales y su relación con la existencia indígena: el caso de la comunidad Anacé y la construcción del Complejo Industrial y Portuario del Pecém en el Estado de Ceará
}

A proteção dos direitos socioambientais e sua relação com a existência indígena: o caso da comunidade Anacé e a construção do Complexo Industrial e Portuário do Pecém no Ceará

Raquel Coelho de Freitas ${ }^{1}$, Thaynara Andressa Frota Araripe ${ }^{2}$, Adrian Esteban Narváez Moncayo ${ }^{3}$

\section{RESUMEN}

El presente estudio busca identificar la experiencia de resistencia vivenciada por el pueblo indígena Anacé ante la construcción del

1 Profesora Asociada de la Universidad Federal de Ceará. Doctora en Derecho Público de la Universidad del Estado de Rio de Janeiro. Magister en Derechos Humanos Internacionales de la Harvard Law School. Especialista en Violencia Urbana de Universidad Federal de Pernambuco.

2 Maestrante en Orden Jurídica Constitucional de la Universidad Federal de Ceará.

3 Abogado de la Universidad Mariana, Colombia. Maestrante en Orden Jurídica Constitucional de la Universidad Federal de Ceará. 
Complejo Industrial y Portuario del Pecén en el Estado de Ceará frente a los intensos daños socio-ambientales que tal emprendimiento causó en su territorio. En ese contexto, la investigación pretende, a través de estudios bibliográficos, documentales y legislativos, comprender no solo los instrumentos jurídicos de protección a los derechos indígenas en Brasil teniendo como marco la Constitución Federal de 1988 y el pluralismo jurídico, sino también la noción de territorio tradicionalmente ocupado como un complejo sistema vital de relaciones entre naturaleza, seres espirituales y cultura. Así, la no demarcación de las tierras indígenas Anacé está directamente ligada a la degradación del patrimonio material e inmaterial, a la contaminación y degradación ambiental, a la destrucción de los recursos hídricos, a la discriminación y negación de la autodeterminación, o sea, al derecho de existir de los pueblos indígenas en el Estado de Ceará.

Palabras clave: Pueblos indígenas. Derechos socio-ambientales. Pluralismo jurídico.

\section{RESUMO}

O presente estudo busca identificar a experiência de resistência vivenciada pelo povo indígena Anacé perante a construção do Complexo Industrial e Portuário do Pecém no Ceará diante dos intensos danos socioambientais que tal empreendimento causou em seu território. Nesse contexto, a pesquisa pretende, através de estudos bibliográficos, documentais e legislativos, compreender não só os instrumentos jurídicos de proteção aos direitos indígenas no Brasil tendo como marco a Constituição Federal de 1988 e o pluralismo jurídico, mas também a noção de território tradicionalmente ocupado como um complexo sistema vital de relações entre a natureza, seres espirituais e cultura. Assim, a não demarcação das terras indígenas Anacé está diretamente ligada à degradação do patrimônio material e imaterial, à contaminação e à degradação ambiental, à destruição dos recursos hídricos, à discriminação e à negação da autodeterminação, ou seja, ao direito de existir dos povos indígenas no Ceará. 
Palavras-chave: Povos indígenas. Direitos socioambientais. Pluralismo jurídico.

\section{INTRODUCCIÓN}

La construcción del Complejo Industrial y Portuario del Pecém en el Estado de Ceará entre los municipios de São Gonçalo do Amarante y Caucaia ha afectado diversas comunidades. Entre ellas, un grupo en especial ha resistido - el pueblo indígena Anacé - por reivindicar una relación diferenciada con tal territorio, lo que presupone otros modelos de uso y gestión de los recursos naturales. Delante de eso, en el presente artículo, se observa, entre expropiaciones violentas, procesos judiciales y daños al medio ambiente, los conflictos envueltos en la construcción del CIPP a través de un abordaje histórico.

Para comprender la violación de derechos sufrida por el pueblo indígena Anacé, es necesario un estudio sobre los instrumentos jurídicos de protección a los pueblos indígenas en Brasil. De esa manera, es resulta de menester importancia resaltar la urgencia de efectivización y fortalecimiento del pluralismo jurídico en el contexto brasileño como mecanismo para fortalecer las autonomías indígenas y su lucha por existir. Para tal efecto, se parte del análisis de la legislación, teniendo como marco referencial la Constitución Federal Brasileña de 1988.

Más adelante, a partir de un análisis bibliográfico, se estudiará el manejo de la preservación al medio ambiente por parte de los indígenas Anacé, en razón de su relación diferenciada con la tierra que ocupan, enfatizando las consecuencias, no solo en los aspectos físicos como la salud, sino también, aspectos culturales y sociales surgidos partir de la construcción del CIPP.

Así, a partir del presente estudio, se buscó identificar la experiencia de resistencia vivenciada por ese pueblo indígena y su relación diferenciada con la tierra como elemento esencial de su existencia. 


\section{EXPERIENCIA DE LA COMUNIDAD INDÍGENA ANACÉ CONTRA LA MERCANTILIZACIÓN DE LA NATURALEZA}

En 1985, la empresa petrolera brasileña Petrobras, anunció el plan de construir una refinería en la región nordeste de Brasil. Con este acontecimiento, se inició una corrida entre los Estados de esta región con el fin de que se crearán condiciones favorables en la disputa, condiciones tales como: infraestructura e incentivos fiscales y de esa manera asegurar el la construcción de tal complejo en sus Estados. El Estado de Pernambuco por su parte, se destacó por ya contar con el Complejo Industrial y Portuario de Suape, pero los estudios apuntaban a los Estados de Ceará y Maranhão como los más adecuados para la instalación de una refinería. Con todo, tal proyecto de Petrobras fue suspendido para la segunda mitad de la década de 1990 por motivos de orden económica y financiera. Sin embargo, la disputa entre los Estado del nordeste continuo.

El Estado de Ceará, por su parte, se dedicó a la construcción del Complejo Industrial y Portuario del Pecém (CIPP). De acuerdo con el pronunciamiento del Secretario Estatal de Transportes, Energía, Comunicaciones y Obras (SETECO) de la época, las confirmaciones y perspectivas de descubrimientos de nuevos pozos de petróleo en el litoral de Paracuru y la infraestructura portuaria del Pecém a implantarse, crearon condiciones para que Petrobras haya tomado una decisión favorable al Estado de Ceará (MAIA JÚNIOR apud AQUINO, 2000 , p. 104). Aconteció que, el área destinada para la construcción de los emprendimientos del CIPP, era ocupada por familias indígenas de la región. De acuerdo a informe por Ana María Matos Araújo:

Con el CIPP, várias comunidades, entre Caucaia y São Gonçalo del Amarante (Pecém), residentes en el espacio, futuro territorio industrial, fueron retiradas obligatoriamente y mediante acción violenta del Estado, que hizo valer su decisión a través de un decreto gubernamental de expropiación, fuerza policial y judicial 
para retirar cerca de 400 familias solamente en Pecém. (ARAÚJO, 2008, p. 4, traducción propia).

Como se observa, centenas de familias fueron expulsadas de sus casas, entre los años 1995 a 1999, siendo algunas realojadas en otros municipios en los asentamientos de Novo Torém, Forquilha y Munguba. En tal acontecimiento, algunas comunidades continuaron luchando en contra del proceso de expropiación que, por repetidas veces, fue muy violento, permitiendo que a través de la unión que la comunidad necesitó, su identidad como comunidad fuera fortalecida y resignificada por una parte y destruida por la otra.

[...] no es de extrañarse que la emergencia de la afirmación étnica de los Anacé se haya dado a partir del riesgo de ser removidos de sus tierras. La verdad, esa afirmación no tendría por qué haberse dado antes, cuando ellos estaban tranquilos en sus tierras y la carga semántica relacionada al designativo "indio" era propulsora solamente de estigma y preconcepto. [...] Hasta recientemente, la estrategia de sobrevivencia para los Anacé era ocultar su identidad indígena, así como hoy - después del cambio histórico producido por el reconocimiento por la Carta Constitucional de 1988 del derecho de los pueblos indígenas a la diversidad cultural y a su tierra tradicionalmente ocupada - y la afirmación de su identidad. (BRISSAC, 2008, p. 13, traducción propia).

La negación de la identidad indígena en el Estado de Ceará es marcada por la tentativa de sobrevivencia de los indígenas. Las políticas institucionales de la época en Brasil, fueron en un sentido de "integración" al mundo de los no indios, por tanto, el objetivo, fue, el desaparecimiento de las ideas y de los ideales indígenas. Existir como indígena, era considerado riesgoso, no solo por el estigma causado, sino también riesgoso para la vida misma.

El reconocimiento como indígena parte de una relación diferenciada con la tierra habitada. Con el cambio de política institucional a partir de la Constitución Federal de 1988 y el movimiento de resistencia delante de las expropiaciones, la cultura indígena - por la lucha - se fortaleció. 
Los Anacé se auto reconocieron públicamente como pueblo indígena en el Estado de Ceará.

Delante de la resistencia indígena, los embrollos políticos y las disputas de los otros Estados del nordeste para atraer las industrias, la conclusión del CIPP, se atrasó. Hasta 2007, cuando el Gobierno Federal por medio del Decreto No. 6025 de 22 de enero de 2007, instituyó el programa de aceleración del crecimiento (PAC), que posibilitó recurso para que el CIPP fuese continuado.

El gobernador del Estado de Ceará, por medio del Decreto No. 28.883/2007 del 19 de septiembre de 2007, declaró la utilidad pública para fines de expropiación e implantación de las obras y servicios del parque industrial del Pecém entre los municipios São Gonçalo do Amarante y Caucaia. EI PAC, entonces, además de ampliar el área del proyecto inicial para $335 \mathrm{~km}^{2}$, también sumó: retroporto, ferrovia transnordestina, gasoducto, ampliación de carreteras federales, termoeléctricas y transposición de ríos.

Una nueva fase de expropiaciones se inició. La lucha del pueblo Anacé continuaba. Vale destacar el apoyo de Ministerio Público Federal (MPF) en la elaboración de representaciones, en especial la denuncia (Proceso administrativo No. 1.15.000.001301/2008-38) propuesta del 18 de julio de 2008 sobre la expropiación de las tierras indígenas Anacé de São Gonçalo do Amarante y Caucaia, en razón de la ampliación del portuario del Pecém, solicitando Grupo de Trabajo con el fin de identificar y delimitar la tierra indígena Anacé.

De esa manera, el 07 de noviembre de 2008, fue elaborado el Concepto Técnico No. 01/08, que dice:

[...] hay un número significativo de pequeños agricultores, que se dedican sobre todo al cultivo de hortalizas -según ellos son los mayores productores de "cheiro-verde" (perejil) y lechuga de la región metropolitana de Fortaleza. También trabajan la tierra, cultivando mandioca, frijol, maíz, macaxeira, papa dulce y jerimum. Algunos trabajan en la cría de ganado bovino y caprino, otros son pescadores artesanales. Hay también funcionarios públicos: profesores, agentes de salud y auxiliares de servicios 
generales, además de los jubilados y pensionados. Están los asalariados que trabajan en las industrias de la región como mecánicos, albañiles, carpinteros y obreros. Varios de ellos han trabajado como mano de obra no especializada en las obras CIPP, principalmente con función de aplanar la tierra y en la instalación de la tubería del gasoducto. La progresiva inserción de ellos en la economía regional, con la realización de actividades comunes a la población de baja renda de la región, no modifica, entretanto el vínculo peculiar que tienen con su territorio a partir de sus narrativas, su vivencia ritual e interacciones sociales (BRISSAC, 2008, p. 19-20, traducción propia).

Delante del concepto que apunta a los Anacé como grupos social que se identifica como pueblo indígena y con la demora de la Fundación Nacional del Indio (FUNAI) en iniciar la demarcación de la tierra indígena Anacé, el MPF, a través de la Recomendación No. 59/08, indicó al Gobierno del Estado de Ceará la suspensión de cualquier actividad que correspondiente a expropiación de terrenos en el área identificada, hasta que estuviesen concluidos los estudios de identificación y delimitación de la tierra indígena realizados por FUNAI. El Gobierno del Estado de Ceará, a su vez, cuestionó el Concepto Técnico No. 01/08.

Fue de esa manera cómo surgió la necesidad de elaborar un nuevo Concepto Técnico, que en el caso fue en Concepto Técnico No. 01/09. El Nuevo concepto, acrecentó el debate socioambiental al establecer una relación entre los elementos ambientales y sociales, tales como: clima, plantaciones, actividades laborales y modo de producción. Según tal concepto:

[...] La implantación de los equipamientos relacionados com el CIPP promovió daños socio-ambientales al geosistema ambiental caracterizado por la gran formación vegetal Prelitoral. Estas inversiones fueron realizadas en el área tradicionalmente ocupada por lo Anacé que, en gran parte, no tuvieron en cuenta la permanencia de la comunidad indígena y la cualidad ambiental de los sistemas de usufructo ancestral. Las acciones relacionadas con la implantación y operación de las indus- 
trias promovieron la degradación de las matas y la formación vegetal (utilizada para la caza y colecta de semillas) y de las lagunas y riachuelos, así como de áreas antes utilizadas para actividades de subsistencia. Fueron implantadas sobre Áreas de preservación Permanente (APPs). Para la aplanación de tierras y desenterramiento de las lagunas y riachuelos, varias familias fueron retiradas y extintos los sistemas ambientales de usufructo indígena. (MEIRELES; BRISSAC; SCHETTINO, 2009, p. 51-52, traducción propia).

A pesar de los estudios minuciosamente detallados, no fueron observadas las medidas pertinentes para minimizar o corregir los daños provocados por las industrias en construcción y ya construidas. La existencia del pueblo Anacé se contrapone a los objetivos del CIPP en cuanto territorio portuario e industrial que atiende a una lógica capitalista de explotación a cualquier costo, sin considerar las condiciones específicas de tal comunidad.

Con fundamento en el nuevo concepto, el MPF, presentó, el 10 de diciembre de 2009, la Acción Civil Pública No.001691838.2009.4.05.8100, requiriendo tutela jurisdiccional con el fin de determinar que el Estado de Ceará, se abstenga de cualquier acto expropiatorio en el área Anacé, que no se dé continuidad a cualquier tipo de obras de esta naturaleza y que se asegure la conclusión del trabajo de identificación, delimitación y demarcación de la tierra indígena Anacé. En enero, el juez federal del caso, profirió decisión de rechazo argumentando:

[...] pois a suspensão da implantação dos empreendimentos já licenciados implicará no retardamento da alavancagem do desenvolvimento do Estado, traduzido no adiamento/impedimento da elevação da produção industrial (6 Mta toneladas/ ano de placas de aço semiacabadas, segundo informação de fls. 1368), das receitas públicas e de criação de empregos (6.000, diretos e 15.000, indiretos, segundo informação de fls. 1368), com inegável prejuízo para população do estado. A suspensão de licenças validamente concedidas poderá, ainda, ensejar ações regressivas em face do poder público 
estadual na ordem dos investimentos previstos, penalizando de forma indireta, mais uma vez, a população cearense (prejuízos estimados por desmobilização e remobilização de obra em 50 milhões de reais; por paralisação de 1 milhão e 100 mil reais diários, segundo informações de fls. 893)

Delante de tal posicionamiento, el MPF, presentó una nueva Acción Civil Pública de No. 0002218-23.2010.4.05.8100, con el fin de refutar el argumento de que las obras del CIPP elevarían la economía del Estado de Ceará, toda vez que el presupuesto a utilizar era todo público. El pedido preliminar fue negado nuevamente.

El 20 de octubre de 2010, FUNAI, público la ordenanza No. 1556, constituyendo un grupo técnico compuesto por miembros de FUNAI, del Gobierno del Estado y de los municipios Caucaia y São Gonçalo do Amarante para realizar los estudios pertinentes para la identificación y delimitación del área de ocupación tradicional de la comunidad Anacé.

La ordenanza concluyó, por tanto, que no existía una área tradicional ocupada por los Anacé, (Matões y Bolso), correspondiendo estas, a las áreas más impactadas y de más valor político y económico para el CIPP, ya que allí sería el lugar donde se instalaría la Refinería II de Petrobras.

Delante de esa coyuntura, en el contexto del programa básico ambiental de la refinería Premium II, fue propuesto un programa de Emergencia de reubicación de las familias Anacé de las aldeas de Matões y Bolso para una área, que futuramente sería adquirida por el Estado de Ceará, por Petrobras, FUNAL, el MPF, la Unión y las comunidades indígenas Anacé de Matões y Bolso, con el fin de liberar el terreno donde sería instalada la Refinería Premium II y las demás obras del CIPP y de garantizar la creación de la Reserva Indígena Taba de los Anacé donde serían reorganizadas las 163 familias indígenas.

En 2017, fue propuesta una Acción Popular aliada una Acción Civil Pública, instaurada por la Defensoría Pública de la Unión (DPU-CE) y Defensoría Pública del Estado (DPE-CE) solicitando la paralización de las obras de red de aguas del CIPP. La comunidad indígena alegó la inadmisibilidad del abastecimiento prioritario del CIPP, una vez que el 
Estado de Ceará es marcado por la escasez hídrica, a eso sumando el hecho de que las obras no poseen estudios de impacto ambiental y no respetan el Área de Protección Ambiental (APA) y además violan el derecho de abastecimiento de la población.

Solo fue en fecha de 06 de febrero de 2018, que la comunidad indígena Anacé, recibió la Reserva prometida con 163 residencias, una escuela y un puesto de salud. Después de la decisión de Petrobras de desistir de la refinería, el Gobernador del Estado de Ceará alega, en el discurso de la entrega de la reserva, la deuda de Petrobras, en el sentido que la empresa se había comprometido a pagar la mitad del presupuesto de la obra, pero que no cumplió con lo prometido.

\section{LOS INSTRUMENTOS JURÍDICOS PARA LA PROTECCIÓN DE LOS DERECHOS INDÍGENAS EN EL MARCO DEL PLURALISMO JURÍDICO EN BRASIL.}

La formación histórica y social del continente latinoamericano tiene como característica la diversidad cultural presente, no solo en los pueblos originarios de aquella región, sino también, en las comunidades que se fueron constituyendo por el ingreso de trabajadores esclavos y los nuevos colonizadores a lo largo del tiempo. En la esfera jurídica, eso quiere decir que existe un pluralismo jurídico en razón de la coexistencia de diversos sistemas, cada uno con sus propias características.

De esa forma la coexistencia de diversos sistemas jurídicos dentro de un mismo campo social buscando una administración de justicia de acuerdo con la realidad cultural de quien la demanda, construye, el concepto de pluralismo jurídico. (MASAPANTA GALLEGOS, 2009).

En relación de la contradicción entre la realidad Latinoamérica y el proyecto colonizador eurocéntrico, las diversas formas de violencia vividas en los últimos tiempos, han fomentado el desarrollo de teorías críticas descolonizadoras. La lucha popular en algunos países latinoamericanos ha implicado en la consolidación de nuevos paradigmas que reinventan a través de saberes y prácticas populares 
pre-coloniales, instituciones como: El Estado y la Constitución. Estas transformaciones pueden ser verificadas, tanto en el ámbito jurídico, como también en el ámbito político y que a su vez, son marcadas por diversos niveles de consolidación.

Históricamente en Brasil, hasta la fundación de la Constitución Federal de 1988, la política indigenista que abarcaba todo el escenario político y jurídico del país, era integracionista y asimilacioncita. Contrariamente, la Constitución Federal de 1988, reconoce a los indígenas el derecho de existencia y atribuye a la Unión, el deber de proteger y respetar los bienes indígenas, conforme se observa en algunos de sus dispositivos:

Art. 210. [...].

$\S 2^{\circ}$ - $\mathrm{O}$ ensino fundamental regular será ministrado em língua portuguesa, assegurada às comunidades indígenas também a utilização de suas línguas maternas e processos próprios de aprendizagem.

Art. 215. O Estado garantirá a todos o pleno exercício dos direitos culturais e acesso às fontes da cultura nacional, e apoiará e incentivará a valorização e a difusão das manifestações culturais.

$\S 1^{\circ}$ - O Estado protegerá as manifestações das culturas populares, indígenas e afro-brasileiras, e das de outros grupos participantes do processo civilizatório nacional.

Art. 231. São reconhecidos aos índios sua organização social, costumes, línguas, crenças e tradições, e os direitos originários sobre as terras que tradicionalmente ocupam, competindo à União demarcá-las, proteger e fazer respeitar todos os seus bens.

Art. 232. Os índios, suas comunidades e organizações são partes legítimas para ingressar em juízo em defesa de seus direitos e interesses, intervindo o Ministério Público em todos os atos do processo.

ATO DAS DISPOSIÇÕES CONSTITUCIONAIS TRANSITÓRIAS:

Art. 67. A União concluirá a demarcação das terras indígenas no prazo de cinco anos a partir da promulgação da Constituição. (BRASIL, 1988). 
Por lo tanto, el conjunto de dispositivos que la Constitución Federal de 1988, inaugura, está relacionado con la garantía constitucional de reconocimiento de la existencia de pueblos indígenas con organización social propia. De esa manera, en oposición a la noción de sujeto individual de derecho, tenemos el reconocimiento de los derechos colectivos; en oposición a la idea de propiedad individual de la tierra, tenemos el usufructo del territorio por las comunidades indígenas; en oposición al monismo estatal, tenemos el pluralismo jurídico.

A pesar de que el acápite del artículo 231 de la Constitución Federal de 1988, refiere asuntos de organización social, costumbres, lenguas, creencias y tradiciones indígenas, este todavía, no es suficiente para garantizar el deber ser del pluralismo jurídico en Brasil. El Estatuto del Indio, ley 6001 de 1973, a su vez, hace mención al derecho consuetudinario del indígena.

Pensar y articular un nuevo pluralismo de dimensión política y jurídica es viabilizar las condiciones para la implementación de una política democrática que direcciones y al mismo tiempo produzca un espacio comunitario descentralizado y participativo. La transformación de tal organización físico- espacial y político-institucional no puede ser hecha a corto plazo y no es tan simple, pues las estructuras sociales periféricas como la brasileña, están contaminadas, hasta las raíces por una tradición político-cultural centralizadora, dependiente y autoritaria [...] Parece claro por consiguiente, que la ruptura con este tipo de estructura societaria demanda profundas y complejas transformaciones en las prácticas, cultura y los valores de vida cotidiano. Además de la subversión del pensamiento del discurso y del comportamiento, importa igualmente reordenar el espacio público individual y colectivo, rescatando formas de acción humana que pasan por cuestiones como "comunidade", "políticas democráticas de base", "participación y control popular", "gestión descentralizada", "poder local o municipal" y "sistemas de consejos" (WOLKMER, 2015, p. 249-250, traducción propia).

Conforme se observa en la legislación, en el primer parágrafo del artículo 231 de la Constitución Federal de 1988, es dado el concepto de tierras tradicionalmente ocupadas por los indios. 
$\S 1^{\circ}$ São terras tradicionalmente ocupadas pelos índios as por eles habitadas em caráter permanente, as utilizadas para suas atividades produtivas, as imprescindíveis à preservação dos recursos ambientais necessários a seu bem-estar e as necessárias a sua reprodução física e cultural, segundo seus usos, costumes e tradições.

$\S 2^{\circ}$ As terras tradicionalmente ocupadas pelos índios destinamse a sua posse permanente, cabendo-Ihes o usufruto exclusivo das riquezas do solo, dos rios e dos lagos nela existentes.

(...)

$\S 4^{\circ}$ As terras de que trata este artigo são inalienáveis e indisponíveis, e os direitos sobre elas, imprescritíveis.

$\S 5^{\circ}$ É vedada a remoção dos grupos indígenas de suas terras, salvo, 'ad referendum' do Congresso Nacional, em caso de catástrofe ou epidemia que ponha em risco sua população, ou no interesse da soberania do País, após deliberação do Congresso Nacional, garantido, em qualquer hipótese, o retorno imediato logo que cesse o risco. (BRASIL, 1988).

Es por tanto, una característica traída por la Constitución Federal de 1988, el carácter originario de las tierras indígenas, lo que significa que ningún título o registro, puede ser opuesto contra el derecho de los pueblos indígenas a sus tierras. En los términos del artículo 20 inciso 11 de la Constitución Federal de 1988, las tierras tradicionalmente ocupadas por los pueblos indígenas son propiedad de la Unión Federal, siendo destinadas a la posesión permanente de los indios quienes daban usufructo exclusivo de las riquezas del suelo, ríos y lago en ella existentes.

La habitación de la tierra por los indios en carácter permanente, conjugada con su preocupación tradicional, no debe ser comprendida apenas sobre el aspecto temporal, tal característica debe ser interpretada en relación "al modo tradicional de los indios de ocupar y utilizar las tierras y al modo tradicional de producción, en fin, al modo tradicional de cómo ellos se relacionan como la tierra" (SANTILLI, 2005, traducción propia).

Lo que se ve por tanto en el caso del pueblo Anacé en Ceará, corresponde a una violación explícita del derecho indígena 
constitucional, toda vez que, el pueblo en mención tienen derechos plenos otorgados por la Carta política al entero uso de sus tierras tradicional y ancestralmente ocupadas. Es la forma tradicional de cómo los pueblos indígenas ocupan, producen, construyen, reconstruyen y protegen en todos los sentidos, sus territorios, destacándose aún el sentido proteccionista ambiental de los mismos, como se construye el significado de la tierra como derecho autónomo de los pueblos indígenas.

En ese sentido, se observa que la tierra para los pueblos indígenas no es considerada simplemente como un soporte de especulación de la tierra, basada en una lógica capitalista de lucro y productividad, que generalmente se encuentra muy lejos del concepto proteccionista ambiental y completamente apartado del modo con que los pueblos indígenas observan sus territorios. Toda vez que para ellos, tierra, es un complejo sistema vital de relaciones entre la naturaleza y seres espirituales.

Así, la construcción del Complejo Industrial y Portuario del Pecém, no solo representa un gravísimo daño al entorno ambiental de esta comunidad en específico, sino también una violación directa al derecho a la tierra como elemento fundamental en la esfera de las autonomías de los derechos de los pueblos indígenas dentro del marco del pluralismo brasileño.

\section{EL CUIDADO DEL MEDIO AMBIENTE Y SU RELACIÓN CON EL DERECHO A LA TIERRA COMO ELEMENTO FUNDAMENTAL DE LA EXISTENCIA INDÍGENA}

En el escenario de protección al medio ambiente, las tierras indígenas asumen una posición estratégica. La preocupación global por el cuidado del medio ambiente se ha ido fortaleciendo con el paso del tiempo y en el derecho no ha ocurrido lo contrario.

En el plano internacional, la convención No. 169 de la organización Internacional del Trabajo (OIT), ratificada en Brasil por el decreto 
No. 5.051/04, refuerza ese entendimiento al comprender los pueblos indígenas como detentores de real libertad para el manejo y destino de sus tierras y al considerar que los recursos naturales presentes en esos espacios ambientales son imprescindibles para su sobrevivencia físico espiritual. Por tal motivo la comunidad internacional ha creado diversos mecanismos para atender a esta necesidad, mecanismos tales, que poco a poco, han sido acogidos por los diferentes Estados soberanos. Declaraciones Internacionales como la de Estocolmo de 1972, la Carta Mundial de la Naturaleza de 1982, la Declaración de Río de Janeiro de 1992, entre otras, enfatizan la necesidad de preservar los recursos físicos y biológicos del medio ambiente.

En el contexto indígena, la tierra y su conexión con ella representa un foco de atención principal y puede ser concebido como principal medio de contribución de recursos naturales imprescindibles para la sobrevivencia físico-espiritual y la manutención de los saberes tradicionales (DERANI, 2002). Conforme se explica:

Muchos procesos de territorialización hoy en curso, son procesos de lucha por el significado y la apropiación del medio ambiente (quilombolas, indígenas, vazanteiros, geraizeiros, etc.) contra la apropiación global por el capital, que transforma territorios sociales en espacios abstractos, o sea, lugares en espacios que contienen recursos naturales para explotación capitalista. Entre tanto, los grupos sociales sujetos a expropiación, no son víctimas pasivas y expresan otras formas de existencia en los lugares. Reivindican el derecho a la memoria y a su reproducción social. Y son ellos quienes dicen que no todo está condenado a convertirse en espacio de apropiación abstracta por el capital. (ZHOURI E OLIVEIRA, 2010, p. 445, traducción propia.)

Conforme se observa, el fenómeno de crecimiento económico a cualquier precio de acumulación material de riquezas y la negligencia de desarrollo privado y estatal en cuanto a los impactos ambientales generados para los pueblos indígenas y sus territorios ha generado incompatibilidades sobre la perspectiva de los derechos socioambientales, debatidas en el escenario actual. 
En el Estado de Ceará, sobre el pretexto de desarrollo a cualquier costo, el Complejo Industrial y Portuario del Pecém, fue implementado como una escogencia política y económica gubernamental para la comprensión del desarrollo en una lógica del mercado, sin llevar a consideración las demandas concretas y colectivas del pueblo indígena Anacé, que tiene una dimensión diferenciada con ese mismo territorio.

Tal relación, además de ser pautada en la preservación de los elementos naturales, en el conocimiento de los ciclos climáticos y en la producción sostenible de pequeñas plantaciones, es también basada en la conexión espiritual con la tierra de sus antepasados y con la danza toré. El lugar habitado por los Anacé, por tanto, es donde ellos reproducen su existencia diferenciada. Son ejemplos de los impactos socio-ambientales, causado por la obra del CIPP al pueblo Anacé: Enfermedades respiratorias causadas por el aumento de la polución, polución de los nacimientos de los ríos y secamiento de las lagunas de abastecimiento a la comunidad, además de especulación inmobiliaria, aumento de la violencia, del tráfico de drogas y de la prostitución de la región.

De esa manera, se percibe la incompatibilidad de sobreponerse, en el mismo lugar, el proyecto de desarrollo de CIPP y el área de morada y reproducción de vida de los Anacé. Como se observa, es mucho mayor que una troca de territorios, siendo que para los indios Anacé, representa la pérdida simbólica y material de su casa, su historia y su espiritualidad. Delante de eso:

[...] Las categorías de lugar y territorialidad ganan nuevos contornos y tonalidades al colocarse como contrapunto no provinciano y emancipador de las categorías colonizantes/ colonizadoras forjadas a partir de presuntas posiciones globales (por ejemplo, desarrollo sostenible y gobernanza global). [...] Ese nuevo conjunto de reflexiones, denuncia las categorías del pensamiento que aprisionan la visión a partir de un referencial de modernidad - que sería eurocéntrico, global y masculino, centrado en los procesos del capital, del espacio, de la abstracción. (ZHOURI E OLIVEIRA, 2010, p. 442, traducción propia). 
La necesidad de preservar los recursos físicos y biológicos de las tierras indígenas y sus propios aspectos histórico-culturales, hace pensar ese lugar como un espacio ambientalmente protegido, que requiere un sistema de protección amplia de su ecosistema, considerándose todos sus elementos en conjunto y no de forma independiente. (CANOTILHO, 2008). Entonces, en el contexto de la tutela de los recursos naturales en tierras indígenas, no es suficiente pensar en la actuación de instrumentos que estimulen solamente la preservación de los bienes ambientales materiales. El conjunto de creencias, mitos y conocimientos tradicionales no pueden ser desasociados de las directrices que en su deber ser dirigen la gestión de los recursos naturales en tierras indígenas.

La conservación ambiental de las tierras indígenas, por tanto, envuelve la protección de la diversidad cultural y de la diversidad biológica, que puede tener como resultado la agro-biodiversidad, que, a su vez, está ligada a la alimentación y la cultura, relacionadas a la sobrevivencia física y cultural de la sociedad indígena. (PASCUCHI, 2007).

Por consiguiente, los valores culturales de los pueblos indígenas están vinculados en una relación concreta entre la naturaleza y la cultura, la espiritualidad y sus organizaciones sociales, así como también, la protección del medio ambiente. Naturaleza y cultura están, por tanto, íntimamente relacionadas e interdependientes.

\section{CONSIDERACIONES FINALES}

La realidad vivenciada por el pueblo Anacé en São Gonçalo do Amarante y Caucaia en el Estado de Ceará delante de los impactos de la instalación del Complejo Industrial y portuario del Pecém, invita a reflexionar sobre los derechos socio-ambientales y el modo como los pueblos indígenas tiene una relación diferenciada con el territorio. Conforme se percibió los grandes emprendimientos industriales se alojan en territorio indígena, sin considerar los intereses, la espiritualidad, los modos de producción, la tradición de aquel lugar, negligenciando así, el derecho de existir indígena y transformando las comunidades en nichos de degradación ambiental. 
Se percibe que existen diversas lógicas de comprensión sobre lo que es territorio. La tierra, para los pueblos indígenas, es un complejo sistema vital conjugado por varios elementos de diversa índole y no solamente un soporte de especulación encerrada en una lógica productivista. Es el método tradicional como los pueblos indígenas ocupan, producen, construyen y reconstruyen significados en la tierra indígena cearense que se constituye como territorio.

Por un lado, los pueblos indígenas, en la lucha por reconocimiento de sus especificidades culturales presionan al Judiciario a construir una nueva concepción de justicia que incluya identidades. Y por otro lado, los propietarios privados y, por varias veces, hasta el propio Estado, insisten en mantener el modelo conservador de interpretación basado en el paradigma de inferioridad. Véase, entonces, que el colonialismo, además de años de exploración y silenciamiento, también deja, fuertemente, un legado epistemológico del eurocentrismo que sigue a producir y reproducir definiciones jurídicas que subalternan a los pueblos indígenas.

A pesar del avance de la Constitución brasileña de 1988, en relación al acápite del artículo 231, se observa que todavía no se reconoce con real eficacia el pluralismo indígena en Brasil. El judiciario, por su parte, se mantiene conectado a los paradigmas del colonialismo. Queda, entonces, el desafío de pensar y poner práctica estrategias de superación de ese racismo institucional, además de la construcción de modelos de justicia que se sobrepongan a superar la barrera de la figura de monismo estatal.

\section{REFERÊNCIAS}

ARAÚJO, Ana Maria Matos. Urbanização litorânea nordestina: os casos de Pecém e do Arpoador - Ceará. In: XVI Encontro Nacional de Estudos Populacionais, 2008, Caxambu/MG. Anais do Encontro Nacional de Estudos Populacionais. Caxambu/MG: ABEP, 2008. Disponible en: <http://www.abep.nepo.unicamp.br/encontro2008/ docsPDF/ABEP2008_1897.pdf> Acceso en: 14 de set. 2018. 
BRASIL. Constituição da República Federativa do Brasil, de 5 de outubro de 1988. Disponible en: <http://www.planalto.gov.br/ccivil_03/ Constituicao/Constituicao.htm>. Acceso en: 15 set. 2018.

BRISSAC, Sérgio. A etnia Anacé e o Complexo Industrial e Portuário do Pecém. Parecer Técnico $n^{\circ}$ 01/08. Ministério Público Federal, Fortaleza, 2008.

CANOTILHO, José Joaquim Gomes (Org.). Direito Constitucional Ambiental Brasileiro. $2^{\mathrm{a}}$ ed. São Paulo: Saraiva, 2008.

DERANI, Cristiane. Patrimônio Genético e conhecimento tradicional associado: considerações jurídicas sobre seu acesso. In: LIMA, André (Org.). $\mathrm{O}$ direito para o Brasil socioambiental. Porto Alegre: Sergio Antonio Fabris, 2002.

NOBREGA, Luciana Nogueira; JOCA MARTINS, Martha Priscylla Martins. O Povo Indígena Anacé e o Complexo Industrial e Portuário do Pecém: tessituras socioambientais de um admirável mundo novo. In: Marcos Wachovicz; João Luis Nogueira Matias. (Org.). A Efetivação do Direito de Propriedade para o Desenvolvimento Sustentável: relatos e proposições. 1ed. Florianópolis: Boiteux, 2010, v. , p. 318-343.

MAIA JÚNIOR, Francisco Queiroz apud AQUINO, Jakson Alves. Processo decisório no Governo do Estado do Ceará (1995-1998): o porto e a refinaria. 2000. Fortaleza: Programa de Pós-Graduação (Mestrado) em Sociologia na Universidade Federal do Ceará, 2000.

MASAPANTA GALLEGOS, Christian. El derecho indígena en el contexto constitucional ecuatoriano: entre la exigibilidad de derechos y el reconocimiento del pluralismo jurídico. In: ESPINOSA GALLEGOSANDA, Carlos; CAICEDOTAIPA, Danilo. (Edit.). Derechos ancestrales: justicia en contextos plurinacionales. Quito: V\&M Gráficas, 2009.

MEIRELES, Antonio Jeovah de Andrade Meireles; BRISSAC, Sérgio; SCHETTINO, Marco Paulo Fróes. O povo indígena Anacé e sua terra tradicionalmente ocupada. Parecer Técnico n 01/09. Ministério Público Federal, Fortaleza, 2009. 
ORGANIZAÇÃO INTERNACIONAL DO TRABALHO. Convenção n. 169 sobre Povos Indígenas e Tribais e Resolução referente à Ação da OIT. Brasília: OIT, 2011. Disponible en: http://www.planalto. gov.br/ccivil_03/_ato2004-2006/2004/decreto/d5051.htm Acceso en 28 sep. 2018

PASCUCHI, Priscila Mari. Fundamentos Jurídicos da Zona de Amortecimento em Terra Indígena. Manaus: Programa de PósGraduação (Mestrado) em Direito Ambiental na Universidade Estadual do Amazonas, 2007. 128p.

SANTILLI, Juliana. Unidades de Conservação da Natureza, Territórios Indígenas e de Quilombolas: aspectos jurídicos. In: IRIGARAY, C. T. J. $\mathrm{H}$; RIOS, Aurélio Virgílio Veiga (orgs.). O Direito e o Desenvolvimento Sustentável: curso de direito ambiental. São Paulo: Peirópolis; Brasília: IEB - Instituto Internacional de Educação do Brasil, 2005.

WOLKMER, Antonio Carlos. Pluralismo jurídico: fundamentos de uma nova cultura no Direito. 4 ed. Rev. e ampliada. São Paulo: Saraiva, 2015.

ZHOURI, Andréa; OLIVEIRA, Raquel. Quando o lugar resiste ao espaço: colonialidade, modernidade e processos de territorialização. In: ZHOURI, Andréa; LASCHEFSKI, Klemens (Orgs.). Desenvolvimento e conflitos ambientais. Belo Horizonte: Editora UFMG, 2010. 